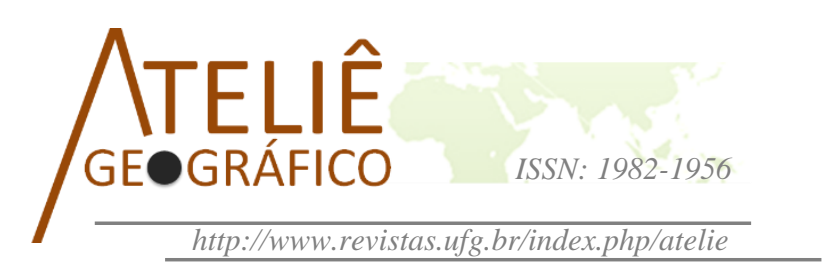

\title{
Abordagem morfopedológica para avaliação histórica da estrutura da paisagem no Vão do Paranã (GO)
}

\author{
Morphological approach for landscape structure historical \\ evaluation in Vão do Paranã (GO)
}

\section{Abordage morfopedologica para avaliación histórica de la estrutura del paisaje en el Vão do Paranã (GO)}

Tássia Andrielle Ponciano

Universidade Federal de Goiás

tassiaponciano@gmail.com

\author{
Hellbia Samara Moreira de Carvalho Rodrigues \\ Universidade Federal de Goiás \\ hellbiageografia1@gmail.com
}

\author{
Karla Maria Silva de Faria \\ Universidade Federal de Goiás \\ karla_faria@ufg.br
}

\begin{abstract}
Resumo
As mudanças no uso e ocupação da terra em áreas de relevância ambiental e social exigem da ciência geográfica análises integradoras da paisagem que ressaltem as relações do meio físico e biótico com as atividades antrópicas. O artigo teve objetivo de analisar o processo histórico de ocupação e as mudanças da estrutura da paisagem entre 1984 e 2015 na microrregião do Vão do Paranã considerando os compartimentos morfopedológicos como unidades de análise integrada da paisagem. A área destaca-se pela relevância ambiental internacional pressionada pelo avanço da fronteira agrícola direcionada de sul e de oeste. A metodologia utilizou-se da análise temporal do uso da terra, avaliando a estrutura da paisagem com uso de métricas e avaliação do comportamento histórico da ocupação e limitações ambientais em compartimentos morfopedológicos. Os resultados indicam a presença de seis compartimentos com processo de fragmentação da vegetação remanescente e avanço exponencial da agricultura em áreas inclusive frágeis. Destacou-se o favorecimento à ocupação antrópica no CMP I e III e a indicação de conservação ambiental nos demais.
\end{abstract}

Palavras-chave: Compartimentos Morfopedológicos; Fragmentação; Métricas da Paisagem. 


\begin{abstract}
Changes in land use and occupation in areas of environmental and social relevance require geographic science to integrate integrative analyzes of the landscape that emphasize the relationships between physical and biotic environment with anthropic activities. The objective of this article was to analyze the historical process of occupation and the changes of landscape structure from 1984 to 2015 in Parana Valley microregion considering the morphopedical compartments as units of landscape integrated analysis. The area stands out due to international environmental relevance pressured by the advance of the agricultural frontier directed from the south and the west. The methodology was based on temporal analysis of land use, evaluating the landscape structure using metrics and assessing the historical behavior of the occupation and environmental limitations in morphopedic compartments. The results indicate the presence of six compartments with process of fragmentation of remaining vegetation and exponential advance of agriculture in areas including fragile ones. Emphasis was placed on the anthropic occupation in CMP I and III and the indication of environmental conservation in the others.
\end{abstract}

Keywords: Morphopedic compartments; Fragmentation; Landscape Metrics.

\title{
Resumen
}

Las mudanzas en el uso y la ocupación de tierras en áreas de relevancia ambiental y social exigen de la ciencia geográfica análisis integradores del paisaje que resalten las relaciones del medio físico y biótico con las actividades antrópicas. El artículo tiene el objetivo de analizar el proceso histórico de ocupación y las mudanzas en la estructura del paisaje entre 1984 y 2015, en la micro-región del Vão do Paranã considerando los distintos compartimientos morfopedológicos como unidades de análisis integrada del paisaje. El área se destaca en el ámbito internacional por la relevancia ambiental y por la presión del avance de la frontera agrícola desde el Sur y Oeste. La metodología utilizada consistió en el análisis temporal del uso de las tierras evaluando la estructura del paisaje con el uso de métricas, el proceso histórico de ocupación y las limitaciones ambientales de los distintos compartimientos morfopedológicos. Los resultados indican la presencia de seis compartimientos con procesos de fragmentación de la vegetación remanente y el avance sostenido de la agricultura en áreas inclusive frágiles. Se destacan condiciones favorables a la ocupación antrópica en los compartimientos CMP I y CMP III y la indicación de conservación ambiental para los demás compartimientos definidos.

Palabras clave: Compartimientos Morfopedológicos; Fragmentación; Métricas de paisaje.

\section{Introdução}

O bioma Cerrado é considerado como uma das áreas mundiais prioritárias (hotspost) para conservação da biodiversidade em função do alto endemismo das espécies e alta pressão antrópica (MITTERMEIER, et al., 2011). Na última década foi alvo de diversos estudos em escalas regionais e locais (MACHADO et al.,2004; SANO et al., 2010; ROCHA et al., 2011; FARIA;CASTRO 2013; FERREIRA et al., 2016) que visaram o monitoramento da configuração e alterações da paisagem, almejando ações de planejamento, políticas de preservação e desenvolvimento sustentável.

Nos últimos cinquenta anos este bioma tem desempenhado um papel importante no desenvolvimento agrícola da região centro-oeste e nacional (REZENDE, 2002; 
GARCIA; BUAINAIN, 2016), destacando-se também por taxas de desmatamento superiores a da Amazônia (INPE, 2017) e rápido processo de fragmentação.

A reversão desse atual quadro de devastação e fragmentação do Cerrado é possível com a revisão de seu modelo de ocupação, sendo o monitoramento de uma região o principal fator para o planejamento racional (ASSAD; SANO, 1998; GANEM; DRUMMOND; FRANCO, 2011). O estudo da paisagem deve, portanto, colaborar com o planejamento territorial considerando as condições de resiliência do ambiente natural e possibilitar aplicações com a preservação da natureza (KLINK, 1981).

A abordagem morfopedológica, evolui dessa proposta, para Castro e Salomão (2000), a compartimentação morfopedológica possui importância singular por se tratar de produto de síntese das relações naturais produzidas por seus fatores de formação e de evolução, que podem ser relacionáveis ao seu histórico de ocupação e formas de utilização, podendo, ainda, revelar-se como instrumentos para os programas de controle preventivo e corretivo de uso do solo.

A proposta da análise integrada da paisagem por estudos morfopedológicos foi utilizada por pesquisadores, como Castro e Salomão (2000), Barbalho (2002), Faria et al. (2013), Nunes (2015) para avaliar conservação do solo e água, destacando o papel do desenvolvimento de processos erosivos, portanto da variável solo. Porém, tal abordagem não foi testada para avaliação das frentes de expansão agrícola e propostas de planejamento territorial e ambiental, o que instiga o questionamento de como os aspectos geoambientais podem ser incluídos na avaliação e proposição de ações de planejamento territorial.

Recentemente as mudanças nos padrões de uso na região sul do estado de Goiás, com a substituição de áreas antes ocupadas por grãos (sobretudo a soja) e pasto pelo cultivo da cana de açúcar (CASTRO et al., 2010), vem gradativamente incorporando a região Nordeste do Estado de Goiás, especialmente a microrregião do Vão do Paranã ao processo de modernização agrícola (FELFILI et al., 2005; FERREIRA et al., 2009; SANTOS; FARIA, 2017).

O estímulo ao desenvolvimento tecnificado agrícola é justificado pelo histórico discurso da ausência ou deficiência de políticas públicas efetivas que contribuíssem para o desenvolvimento e infraestrutura da região que resultou historicamente em um dos piores índices de PIB per capita do Estado de Goiás (YAZIGI, 2000; BORGES et al., 2012) e, que consequentemente inclui a microrregião do Vão do Paranã como uma das áreas prioritárias para desenvolvimento sócioeconômico caracterizadas como "Territórios da Cidadania".

Esta microrregião, no entanto, contempla a II Fase da Reserva da Biosfera do Cerrado (RESBIO Cerrado), área de alta relevância ambiental, que corresponde a um dos três principais centros de endemismo do Cerrado (FELFILI et al., 2005); cerca de $35 \%$ da área total da microrregião encontra-se inserida nas classes de alta e muito alta prioridade para preservação da biodiversidade (MMA, 2015). Trata-se, portanto, de uma área frágil em aspectos econômicos, sociais e ambientais, que apresenta relevância 
histórica ao processo de ocupação do cerrado e do estado de Goiás, que merece ser avaliada sob perspectiva holística e integrada da paisagem

Como os compartimentos morfopedológicos são unidades físicas homogêneas da paisagem, a utilização de seus limites pode auxiliar na avaliação dos eixos preferências de ocupação histórica do Vão do Paranã, que ao se integrar a análise da estrutura da paisagem pode ser possível identificar os padrões e processos ocorrentes que favorecem o planejamento ecológico da paisagem em diferentes escalas, assim como inferir se tal processo de ocupação considerou os níveis de estabilidade, aptidões agrícolas bem como fragilidades e conflitos de uso.

Nesse sentido, o objetivo desse artigo é analisar o processo histórico de ocupação e as mudanças da estrutura da paisagem entre 1984 e 2015 na microrregião do Vão do Paranã considerando os compartimentos morfopedológicos como unidades de análise.

\section{Materiais e Métodos}

\section{Área de Pesquisa}

As características favoráveis, como localização privilegiada, disponibilidade de terra, topografia (relevos planos) e solos de boa aptidão ou facilmente corrigíveis quimicamente por técnicas de calagem, restringiu as maiores e contínuas manchas de vegetação remanescente que concentram-se principalmente na sua porção nordeste, notadamente no Vão do Paranã (SANO et al., 2008), que abriga uma vegetação de mosaicos onde se intercalam florestas estacionais, cerrado sensu scricto, matas de galeria e campos (SILVA et al., 2004).

A microrregião, possui 17.388,88 $\mathrm{km}^{2}$ de área total, constituída por 12 municípios (Figura 01) (Divinópolis, São Domingos, Flores, Iaciara, Guarani, Posse, Mambaí, Buritinópolis, Simolândia, Alvorada do Norte, Damianópolis e Sítio D’abadia) com cerca de 104.388 habitantes (IBGE, 2010).

Os aspectos físicos dessa microrregião a caracterizam em um compartimento homogêneo relacionado ao domínio da Depressão Pediplanada limitada à leste pelo Planalto do Divisor São Francisco-Tocantins e a oeste pelo Planalto Central Goiano, que desenvolveu-se sob o domínio geológico de rochas da Faixa de Dobramentos Brasília, sendo relacionados a metassedimentos de baixo grau metamórfico do grupo Bambuí com idades de deposição de 700 e 600 milhões de anos (EMBRAPA, 2001). O desenvolvimento pedológico, no entanto é diversificado, com destaque à presença dos Latossolos Vermelhos Amarelos, Plintossolos Pétricos e Argissolos, que correspondem juntos a mais de $50 \%$ da área de estudo (PONCIANO, 2017). Destaca-se que tais solos são predominantemente frágeis à compactação e favoráveis ao desenvolvimento de erosões. 


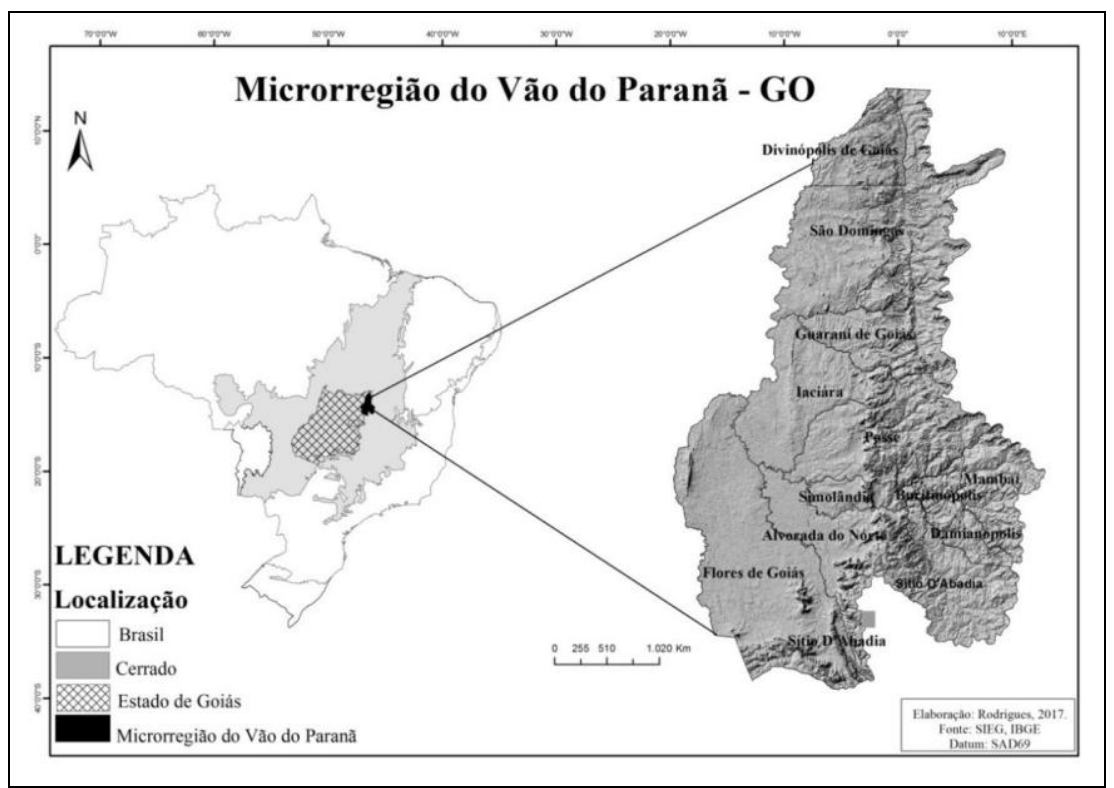

Figura 01: Mapa de localização do Vão do Paranã.

Elaboração: PONCIANO, T. A; RODRIGUES, H. S. M; FARIA, K. M. S., 2017

A área apresenta, portanto, limitações ambientais, como estresse hídrico decorrente da condição climática, solos frágeis e com baixa aptidão para atividades de monoculturas; a aptidão agrícola é para as atividades pastoris em função de extensas áreas de várzeas de pastagens naturais, utilizadas na seca e com campinas nos chapadões (BARREIRA, 2002; HERMUCHE; SANO 2011)

Historicamente a área apresentou expressividade econômica, reconhecida em todo o estado de Goiás pela relevância na pecuária, que foram intensificadas no século XIX, principalmente em áreas de fronteira com estado baiano e mineiro (BARREIRA, 2002) e recentemente retoma projetos de desenvolvimento econômico ao ser inserida como Território da Cidadania Nacional ${ }^{1}$.

\section{Procedimentos Metodológicos}

No campo de atuação da Geografia a análise integrada da paisagem é proposta por meio da definição e delimitação de compartimentos da paisagem que ressalte as relações do meio físico/biótico com as atividades antropogênicas (TRICART, 1977).

A compartimentação morfopedológica, proposta nesse trabalho, adotou a recomendação de Castro e Salomão (2000), sendo gerada a partir da superposição

\footnotetext{
${ }^{1}$ Os Territórios da Cidadania correspondem a uma estratégia de desenvolvimento regional sustentável para garantia de direitos sociais voltado às regiões que necessitam de desenvolvimento econômico e acesso aos programas básicos de cidadania (BRASIL, 2008).
} 
cartográfica, ajustando a escala para manter a uniformidade dos mapas, referentes ao substrato litológico, solos, relevo e hipsometria sobre base topográfica (1:100.000).

A aquisição cartográfica e temática do substrato geológico foi compilada de forma gratuita da base de dados do Sistema Estadual de Estatística e de Informações Geográficas (SIEG); os dados de hipsometria e declividade foram elaborados com uso da SRTM (Shutle Radar Topographic Mission, com resolução de $30 \mathrm{~m}$ ), que auxiliou ainda na adequação dos limites do mapa de geomorfologia nas unidades propostos para o estado de Goiás por Latrubesse e Carvalho (2006); o mapa de solos também foi refinado com dados da SRTM e ALOS PALSAT, acompanhado de dados de campo e descrição de perfil morfológico de solos.

Ressalta-se que o refinamento da base de dados Geomorfologia, Pedologia compõem objetivos secundários de projeto do $\mathrm{CNPq}$ ao qual essa pesquisa se vincula.

A delimitação dos compartimentos morfopedológicos no primeiro nível de tratamento na escala de semi-detalhe: 1:100.000, foi desenvolvida com base na correção espacial positiva entre os dados cartográficos organizados, avaliando-se regiões homogêneas (Figura 02).

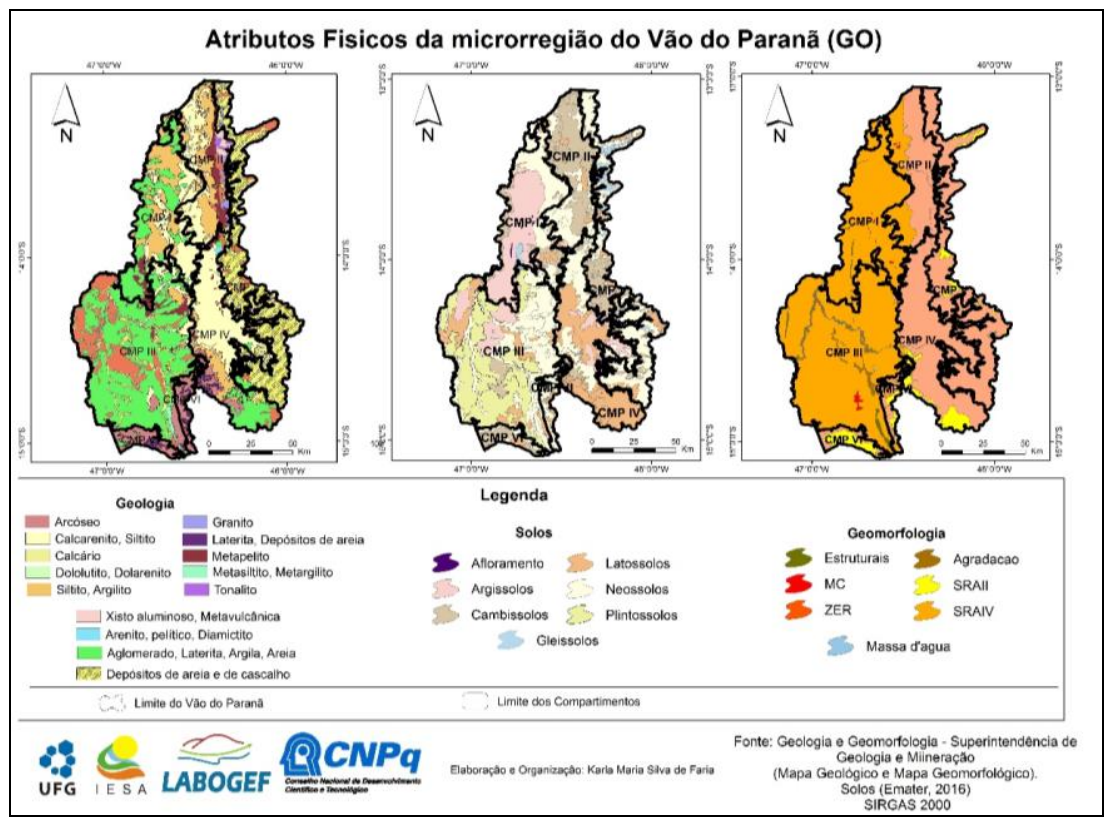

Figura 02: Delimitação dos Compartimentos Morfopedológicos.

Elaboração: FARIA, K. M. S. Faria, 2018.

A dinâmica das atividades antropogênicas na paisagem foi avaliada para um período de 30 anos, considerando imagens do sistema Landsat (mês de julho, no recorte temporal dos anos de 1984 e 2015), que foram interpretadas e classificadas conforme 
proposta metodológica de Faria e Castro (2013) e posteriormente sobrepostas ao mapa de compartimentos morfopedológicos.

Foram avaliadas as características ambientais de cada compartimento e possível relação com a estrutura da paisagem em nível de paisagem segundo as métricas de área total das classes (CA); Percentagem de fragmentos de mesma classe na paisagem (PLAND) e Número de fragmentos da classe (NP), obtidas no software Fragstat ${ }^{\circledR}$ (MCGARIGAL; MARKS, 1995) para cada ano avaliado.

\section{Resultados e Discussão}

Evolução da Estrutura da Paisagem na Microrregião do Vão do Paranã entre 1984 e 2015

Os mapas de uso e cobertura da terra dos anos analisados (Figura 03) indicam que predominantemente, a vegetação remanescente concentra-se na porção leste da microrregião, que coincide com áreas com relevo mais movimentado, onde atualmente encontram se as Unidades de Conservação Estaduais e Federais; na porção oeste se encontram as áreas de maior impacto antrópico, com predominância da agricultura e pastagens.

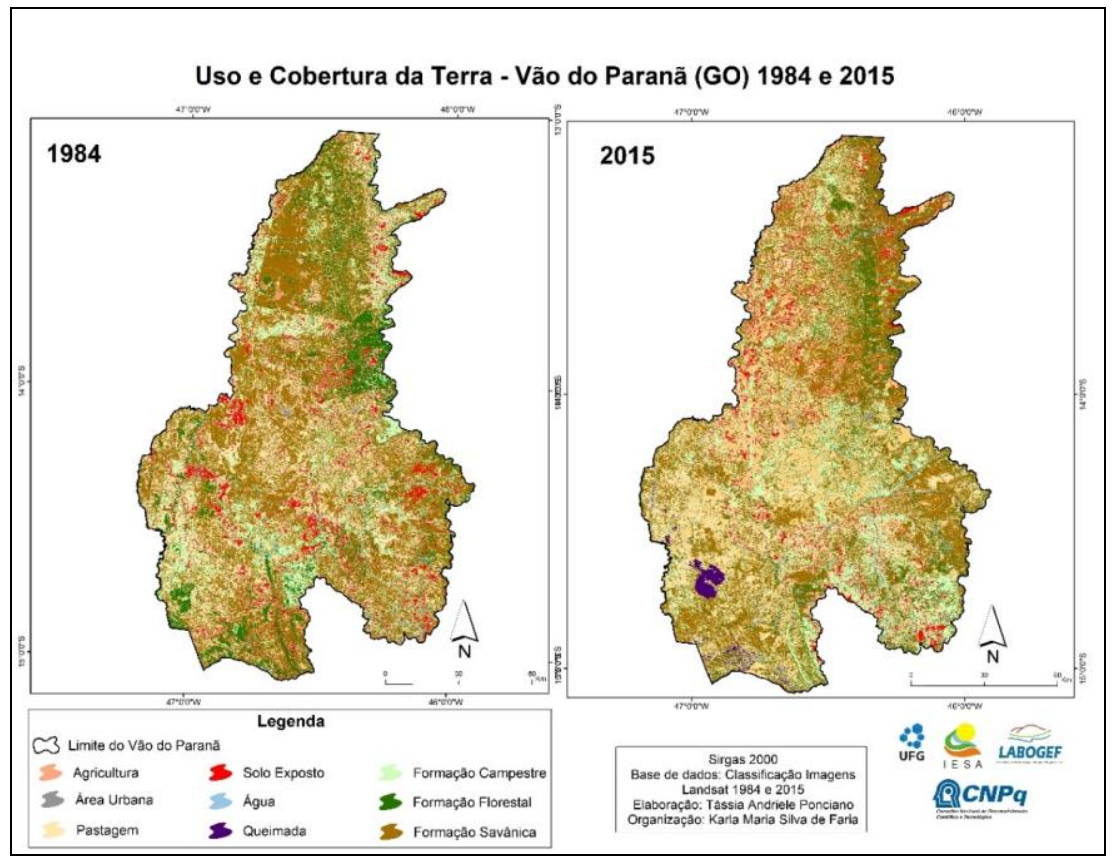

Figura 03: Evolução do uso e cobertura do solo, nos anos 1984 a 2015.

Elaboração: Tássia A. Ponciano, 2017. 
O mapeamento de 1984 corrobora os dados históricos e atuação das políticas públicas de desenvolvimento da região, como o Programa de Desenvolvimento dos Cerrados (POLOCENTRO) e o Programa de Cooperação Nipo-Brasileira de Desenvolvimento dos Cerrados (PRODECER) e a vocação pastoril da região. As áreas de pastagens são identificadas na porção centro-sul, nos municípios de Iaciara, Posse e Flores de Goiás grandes manchas da classe pastagens; a agricultura, com menor expressividade, apresentava-se pontual no Vão do Paranã. No ano de 2015 as pastagens e a agricultura dividem e dominam o lado oeste do Vão do Paranã, principalmente ao centro.

Embora tenha ocorrido aumento nas áreas agrícolas, a inspeção visual das imagens indica que são poucas as grandes áreas de monoculturas. Existem, aproximadamente, 44 assentamentos na região que foram estimulados para o processo de ocupação da área bem como em atendimento a políticas de reforma agrária (SANTOS, 2016). A presença desses assentamentos possibilita a tipificação de regiões com alto nível de antropização, fragmentação da vegetação natural e a tipificação de paisagens quadriculadas (LANG; BLASCHKE, 2009).

A análise da estrutura da paisagem com uso das métricas indicam a situação da evolução da cobertura de remanescentes de vegetação nativa e uso da terra através das métricas CA, PLAND e NP (Tabela 01).

Tabela 01: Análise da evolução da paisagem do Vão do Paranã de 1984 a 2015. Unidade métrica: CA (ha) e PLAND (área em \%).

\begin{tabular}{|c|c|c|c|c|c|c|}
\hline \multirow[b]{2}{*}{ Classe de Uso } & \multicolumn{3}{|c|}{1984} & \multicolumn{3}{|c|}{2015} \\
\hline & CA (ha) & PLAND (\%) & NP & CA (ha) & $\begin{array}{c}\text { PLAND } \\
(\%)\end{array}$ & $\mathbf{N P}$ \\
\hline Formação Campestre & $2.871,19$ & 16,57 & 195.248 & $2.802,55$ & 16,12 & 199.731 \\
\hline Formação Florestal & $1.712,70$ & 9,88 & 103.595 & $1.640,12$ & 9,44 & 121.994 \\
\hline Formação Savância & $7.083,60$ & 40,87 & 168.357 & $5.793,39$ & 33,33 & 193.186 \\
\hline Classes remanescentes & $11.667,49$ & 67,32 & 467.200 & $10.236,07$ & 58,88 & 514.911 \\
\hline Agricultura & 44,43 & 0,26 & 142 & $2.548,27$ & 14,66 & 141.438 \\
\hline Área Urbana & 22,97 & 0,13 & 42 & 29,22 & 0,17 & 33 \\
\hline Pastagem & $4.031,89$ & 23,26 & 143.544 & $3.107,23$ & 17,87 & 175.467 \\
\hline Solo Exposto & $1.258,12$ & 7,26 & 66.797 & 914,44 & 5,26 & 64.060 \\
\hline Classes antrópicas & $5.357,41$ & 30,91 & 210.525 & $6.599,19$ & 37,96 & 381.098 \\
\hline Água & 207,18 & 1,20 & 9.331 & 308,08 & 1,77 & 26.196 \\
\hline Queimada & 98,42 & 0,57 & 810 & 187,93 & 1,08 & 13.320 \\
\hline Outros usos & 305,60 & 1,76 & 10.141 & 548,1 & 3,15 & 43.391 \\
\hline Total ( $\sum$ dos Subtotais) & $\mathbf{1 7 . 3 3 0 , 5 0}$ & 100 & 687.866 & $17.383,37$ & 100 & 939.400 \\
\hline
\end{tabular}

Elaboração: PONCIANO, T. A.; RODRIGUES, H. S. M. de C; FARIA, K. M. S., 2017.

Ao se analisar os dados referentes às métricas das áreas antropizadas (área urbana, pastagem, agricultura e solo exposto) constata-se que em 1984 elas 
correspondiam a aproximadamente $31 \%$ da área total, crescendo até o ano de 2015 , em torno de $7 \%$, destacando-se o ganho em área da classe de agricultura, que amplia em mais de $14 \%$.

A análise comparativa entre as métricas permite constatar o processo de decréscimo de $8 \%$ para as classes de remanescentes, especialmente da Formação Savânica. Esta formação apresenta o estrato vegetativo que permite que o gado adentre a vegetação promovendo degradações nas bordas e no interior da mancha com a abertura de clareiras, comprometimento da vegetação de sub-bosque e alteração na biota do solo (CARVALHO et al., 2009; ALVES et al., 2011; FARIA et al., 2012) e a predominância, dentre os usos antrópicos de pastagens no ano de 2015 pode ser umas principais causas da fragmentação da vegetação dessa formação, que ampliou em 24.829 fragmentos ( $\neq$ de NP entre 1984 e 2015).

A fragmentação da paisagem pode ser avaliada também pelo aumento nas demais formações e nos usos antrópicos, que indica uma crescente fragmentação da cobertura de vegetação remanescente da área.

Conforme metodologia apresentada, considerando escala e critérios adotados, foram definidos para a área seis compartimentos morfopedológicos (Figura 04 e Quadro $01)$.

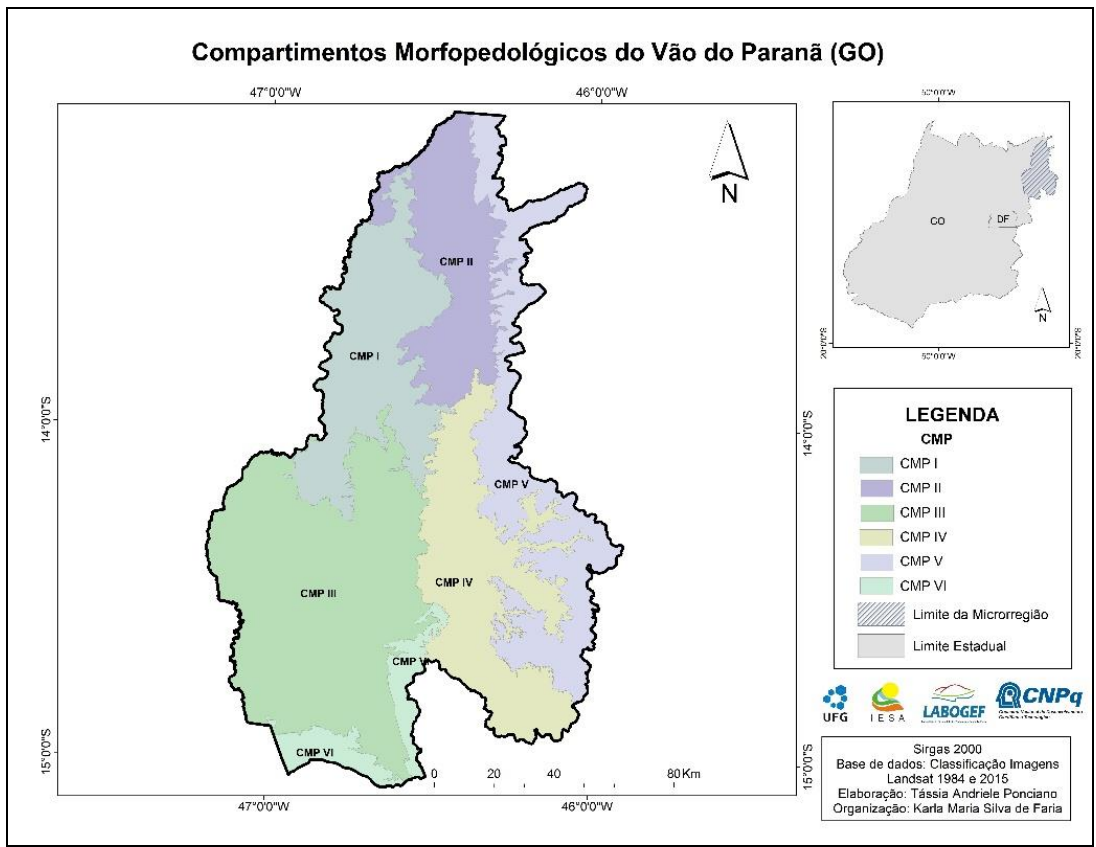

Figura 04: Mapa de compartimentação morfopedológica do Vão do Paranã.

Elaboração: PONCIANO, T. A, 2017. 
Quadro 01: Síntese das características dos Compartimentos Morfopedológicos

\begin{tabular}{|c|c|c|c|c|}
\hline & \multicolumn{4}{|c|}{ Aspectos ambientais predominantes } \\
\hline CMP & Pedologia & Geomorfologia & $\begin{array}{c}\text { Uso do Solo em } \\
1984\end{array}$ & $\begin{array}{c}\text { Uso do Solo em } \\
2015\end{array}$ \\
\hline $\mathbf{I}$ & Argissolos (72\%) & $\begin{array}{c}\text { Superfície Regional de } \\
\text { Aplainamento IVA-LA } \\
\text { (dissecação fraca) }\end{array}$ & $\begin{array}{c}\text { Formação Savânica } \\
(53,6 \%)\end{array}$ & Agricultura $(25,1 \%)$ \\
\hline II & $\begin{array}{l}\text { Cambissolos } \\
\text { Háplicos (45\%) }\end{array}$ & \begin{tabular}{|c|} 
Zona de Erosão \\
Recuante e Superfície \\
Regional de \\
Aplainamento IVA- \\
IIA(dissecação muito \\
forte)
\end{tabular} & $\begin{array}{c}\text { Formação Savânica } \\
(47,7 \%)\end{array}$ & $\begin{array}{c}\text { Formação Savânica } \\
(40,9 \%)\end{array}$ \\
\hline III & $\begin{array}{c}\text { Plintossolos Pétricos } \\
(50 \%)\end{array}$ & $\begin{array}{c}\text { Superfície Regional de } \\
\text { Aplainamento IVA-LA } \\
\text { (dissecação fraca) }\end{array}$ & $\begin{array}{c}\text { Formação Savânica } \\
(40,4 \%)\end{array}$ & $\begin{array}{c}\text { Formação Savânica } \\
(35,2 \%)\end{array}$ \\
\hline IV & Latossolos (28\%) & $\begin{array}{c}\text { Zona de Erosão } \\
\text { Recuante e Superfície } \\
\text { Regional de } \\
\text { Aplainamento IVA- } \\
\text { IIA(dissecação muito } \\
\text { forte) } \\
\end{array}$ & $\begin{array}{c}\text { Formação Savânica } \\
(38,5 \%)\end{array}$ & $\begin{array}{c}\text { Formação Campestre } \\
(26,6 \%)\end{array}$ \\
\hline $\mathbf{V}$ & $\begin{array}{c}\text { Neossolos } \\
\text { Quartzarênicos } \\
(63 \%)\end{array}$ & $\begin{array}{c}\text { Zona de Erosão } \\
\text { Recuante (dissecação } \\
\text { muito forte) e } \\
\text { Superfície Regional de } \\
\text { Aplainamento IVA-LA } \\
\text { (dissecação fraca) } \\
\end{array}$ & $\begin{array}{c}\text { Formação Savânica } \\
(41,3 \%)\end{array}$ & $\begin{array}{c}\text { Formação Savânica } \\
(44 \%)\end{array}$ \\
\hline VI & $\begin{array}{l}\text { Cambissolos } \\
\text { Háplicos }(68 \%)\end{array}$ & $\begin{array}{l}\text { Zona de Erosão } \\
\text { Recuante }\end{array}$ & $\begin{array}{c}\text { Formação Savânica } \\
(40,6 \%)\end{array}$ & $\begin{array}{c}\text { Formação Savânica } \\
(31,1 \%)\end{array}$ \\
\hline
\end{tabular}

Fonte: Mapa de compartimentação morfopedológica do Vão do Paranã (2017)

O CMP I (16,22\% da área) localiza-se na porção oeste da área de estudo, apresenta solos mais estáveis (Latossolos e o Argissolos), que se devolveram em relevos aplainados com declividade plana a suavemente ondulada, que podem ser incorporados ao processo produtivo agrícola sem grandes limitações de aptidão. É portanto, o CMP que apresenta menor limitação ao processo de ocupação, em função do solo e da topografia.

O CMP II (12,8\% da área) localizado na porçõe norte da área de estudo, apresenta o predomínio de solos jovens (Cambissolos; Neossolos Litólicos e Neossolos Quartzarênicos) condicionados a distintos processos evolutivos geomorfológicos em uma zona de transição entre a Zona de Erosão Recuante e as Superfícies Regionais de Aplainamento onde ocorrem 
feições cársticas. Apresentam restrições quanto ao uso ocupação diante da fragilidade de seus componentes físicos e químicos, em alguns ambientes ocorrem em áreas que são prioritárias à conservação como as áreas de preservação permanente.

O maior compartimento corresponde ao CMP III (32,03\% da área), que se localiza na porção sudoeste da área de estudo e destaca-se ainda pelo predomínio dos Plintossolos Pétricos e declividade plana. Tais solos apresentam fortes limitações para o uso de maquinários e outras limitações ligadas a baixa fertilidade natural, acidez elevada e drenagem, e nesse CMP verifica-se a presença de assentamentos rurais que, consequentemente apresentam limitações ao desenvolvimento agrícola.

O menor compartimento CMP VI $(4,48 \%)$, localiza-se na porção sul e caracteriza-se por forte grau de dissecação que estrutura os solos do tipo Cambissólicos. Tal CMP é estruturalmente separado em duas áreas em função de um hogback, pertencente ao CMP III. Localiza em região intermediária entre os compartimentos e sob influência a evolução geomorfológica do CMP V, ao apresentar reentrâncias de cabeceiras de drenagem.

A diversidade pedológica desse compartimento associa-se a uma litologia diversificada e fraca dissecação da Superfície Regional de Aplainamento, o predomínio, no entanto é dos Latossolos Vermelho Amarelos, mas o elevado grau de dissecação do relevo pode ter influenciado diretamente o processo de ocupação, pois de todos os CMPs este é o que apresenta maior densidade de malha viária e interligação com núcleos urbanos. No entanto, o processo de ocupação desse compartimento contradiz com o comportamento da infraestrutura da fronteira agrícola, pois elementos como núcleos urbanos e malha viária, também são variáveis dinamizadoras para consolidação das áreas agropecuárias.

O CMP V (17\% da área) correlaciona-se com o contraforte da Serra Geral de Goiás, caracterizada nos estudos geomorfológicos como Zona de Erosão Recuante, onde predominam os Neossolos Quartzarênicos, solos que apresentam fortes limitações para o uso agrícola e também atividades pastoris, relacionadas à restrição a mecanização e à forte suscetibilidade aos processos erosivos.

O menor compartimento CMP VI (4,48\%), localiza-se na porção sul e caracteriza-se por forte grau de dissecação que estrutura os solos do tipo Cambissólicos. Sendo, como já apresentado estruturalmente separado em duas áreas em função de um hogback, pertencente ao CMP III.

Tabela 02: Análise da evolução da métrica PLAND entre 1984 e 2015 por compartimentos morfopedológicos.

\begin{tabular}{|c|c|c|c|c|c|c|c|c|c|c|c|c|}
\hline & \multicolumn{12}{|c|}{ MÉTRICA PLAND } \\
\hline \multirow{2}{*}{$\begin{array}{c}\text { Classes de } \\
\text { Uso }\end{array}$} & \multicolumn{2}{|c|}{ CMPI } & \multicolumn{2}{|c|}{ CMPII } & \multicolumn{2}{|c|}{ CMPIII } & \multicolumn{2}{|c|}{ CMP IV } & \multicolumn{2}{|c|}{ CMP V } & \multicolumn{2}{|c|}{ CMPVI } \\
\hline & 1984 & 2015 & 1984 & 2015 & 1984 & 2015 & 1984 & 2015 & 1984 & 2015 & 1984 & 2015 \\
\hline Agricultura & 1,3 & 25,1 & 0,1 & 7,8 & 0,0 & 14,6 & 0,0 & 14,0 & 0,0 & 12,4 & 1,3 & 12,5 \\
\hline Agua & 0,5 & 0,4 & 0,1 & 1,4 & 1,0 & 1,0 & 3,0 & 3,9 & 1,5 & 2,3 & 1,1 & 3,6 \\
\hline Urbano & 0,0 & 0,0 & 0,1 & 0,2 & 0,2 & 0,1 & 0,3 & 0,3 & 0,1 & 0,3 & 0,0 & 0,0 \\
\hline
\end{tabular}




\begin{tabular}{c|c|c|c|c|c|c|c|c|c|c|c|c}
\hline $\begin{array}{c}\text { Classes de } \\
\text { Uso }\end{array}$ & \multicolumn{2}{|c|}{ CMPI } & \multicolumn{2}{c|}{ CMPII } & \multicolumn{2}{c|}{ CMPIII } & \multicolumn{2}{c|}{ CMP IV } & \multicolumn{2}{c|}{ CMP V } & \multicolumn{2}{c}{ CMPVI } \\
\cline { 2 - 14 } & $\mathbf{1 9 8 4}$ & $\mathbf{2 0 1 5}$ & $\mathbf{1 9 8 4}$ & $\mathbf{2 0 1 5}$ & $\mathbf{1 9 8 4}$ & $\mathbf{2 0 1 5}$ & $\mathbf{1 9 8 4}$ & $\mathbf{2 0 1 5}$ & $\mathbf{1 9 8 4}$ & $\mathbf{2 0 1 5}$ & $\mathbf{1 9 8 4}$ & $\mathbf{2 0 1 5}$ \\
\hline Campestre & 11,5 & 10,9 & 16,7 & 14,3 & 14,4 & 15,7 & 17,4 & 26,6 & 19,1 & 12,5 & 28,1 & 21,3 \\
\hline Florestal & 5,7 & 3,1 & 19,8 & 18,6 & 4,2 & 4,2 & 5,3 & 11,8 & 7,1 & 14,8 & 5,8 & 16,8 \\
\hline Pastagem & 20,8 & 22,7 & 11,8 & 12,2 & 32,2 & 27,0 & 26,7 & 12,8 & 20,8 & 9,2 & 16,6 & 11,4 \\
\hline Savânica & 53,6 & 24,9 & 47,7 & 40,9 & 40,4 & 35,2 & 38,5 & 25,2 & 41,3 & 44,0 & 40,6 & 31,1 \\
\hline $\begin{array}{c}\text { Solo } \\
\text { exposto }\end{array}$ & 6,6 & 12,8 & 3,6 & 4,7 & 7,7 & 2,3 & 8,8 & 5,6 & 10,1 & 4,5 & 6,5 & 3,3 \\
\hline TOTAL & $\mathbf{1 0 0}$ & $\mathbf{1 0 0}$ & $\mathbf{1 0 0}$ & $\mathbf{1 0 0}$ & $\mathbf{1 0 0}$ & $\mathbf{1 0 0}$ & $\mathbf{1 0 0}$ & $\mathbf{1 0 0}$ & $\mathbf{1 0 0}$ & $\mathbf{1 0 0}$ & $\mathbf{1 0 0}$ & $\mathbf{1 0 0}$ \\
\hline
\end{tabular}

Fonte: Análise dos dados extraídos dos mapeamentos; Elaboração e organização: PONCIANO, T. A.; RODRIGUES, H. S. M. de C; FARIA, K. M. S., 2018.

A análise comparada entre os usos, no recorte temporal adotado entre os compartimentos (Tabela 02), traz alguns indicativos do comportamento da dinâmica do uso entre os compartimentos.

No CMP I as áreas agrícolas aumentaram cerca de 24\% (353,66 ha), enquanto as classes de pastagens e solo exposto apresentaram baixo crescimento. Avaliando-se, comparativamente os mapas de 1984 e de 2015, percebe-se que as áreas agrícolas desenvolveram-se, sobretudo em áreas de pastagens e Formação Savânica e em menor quantidade na Formação Campestre. Contrapondo as análises de Torbick et al. (2006), tal avanço não possui ligação com infraestrutura, relacionada a posição das vias ou centros urbanos, uma vez que tais infraestruturas são escassas nesse CMP.

O relevo movimentado e solos com alta limitação agrícola do CMP II limitou o processo de ocupação dessa região, sendo este compartimento o mais preservado: menos $9 \%$ da área foram submetidas à incorporação agrícola; as manchas de usos antrópicos ficaram limitadas a porção norte e a vegetação remanescente apresenta manchas contínuas e conservadas, com pouca alteração de usos.

Como a UC de Terra Ronca encontra-se, parcialmente nesse CMP, avaliando-se estratégias para conservação e funcionalidade da área protegida esse dado deve avaliado como positivo, no entanto as restrições agrícolas dessa área indicam um problema de cunho social, pois existem vários assentamentos agrícolas nessa região, o que ampliam problemas de desenvolvimento econômico para os municípios de São Domingos e Divinópolis de Goiás.

O CMP III ao se destacar pela presença de declividade plana, já apresentava no ano de 1984 o predomínio entre os usos antrópicos da classe de pastagens. As limitações agrícolas do solo dominante nesse CMP (Plintossolos) condicionaram que a pastagem mantivesse como uso predominante. As poucas manchas de agricultura desenvolvem-se sob as pequenas manchas de Latossolos Vermelho Amarelos.

A classe de uso da terra dominante em 1984, no CMP IV corresponde à vegetação remanescente, destacando-se a formação Savânica. Como tal CMP abrange parte da área territorial da APA Nascentes do Rio Vermelho, tal informação deve ser avaliada como positiva à conservação ambiental. A análise evolutiva (1984 e 2015) 
indica que os usos antrópicos como pastagens e solo exposto apresentaram decréscimo de área (-16\%) e que a classe de agricultura correspondente a 14\% (no ano de 2015) vincula-se diretamente aos municípios de Posse e Mambaí, em áreas de Argissolos e Latossolos com relevo ondulado.

Ao longo do período analisado, os dados indicam que as pastagens mapeadas em 1984 no CMP V, foram abandonadas em 2015, possivelmente sendo regeneradas as fitofisionomias de cerrado das Formações Savânicas e Florestais, ao norte e desenvolvidas áreas agrícolas, ao sul. Nesse compartimento também são identificados limites territoriais de distintas categorias de unidade de conservação (proteção integral e sustentável), como o Parque Estadual de Terra Ronca, APA Nascentes do Rio Vermelho, Parque Municipal do Pequi. No entanto, o solo pode não se manter como elemento limitante à ocupação agrícola, pois áreas no sudoeste goiano também sobre o domínio de Neossolos Quartzarênicos foram ao longo dos últimos anos incorporadas ao processo produtivo com plantio de cana de açúcar (TRINDADE, 2015).

O CMP VI apresentou crescimento das áreas agrícolas (11,2\%), mas destaca-se também aumento da classe da formação florestal (11\%), esse aumento pode estar está relacionado a possível revegetação na base do hogback, de canais de drenagem presentes nesse CMP que se vinculam às limitações inclusive legais e jurídicas, estabelecidas pela legislação brasileira e estadual na ocupação de áreas de preservação permanente.

Percebe-se, na análise do comportamento do uso entre os compartimentos, uma reordenação do espaço produtivo, que é uma das principais características que, segundo Miziara (2000), qualifica uma frente de expansão, contudo ainda é inexpressivo o avanço da fronteira agrícola, pois se desenvolve a passos lentos na região, quando comparada com outras regiões do estado de Goiás.

\section{Considerações Finais}

A análise comparada entre os usos, no recorte temporal adotado, indica que em geral as áreas de pastagens têm cedido área para a agricultura. A partir das análises dos resultados obtidos pode se inferir que a região encontra se com elevados níveis de fragmentação da paisagem e com predomínio de número de fragmentos pequenos em todas as classes de remanescentes. Situação a qual remete os fragmentos a maiores efeitos, de composição e configuração, advindos do processo de fragmentação da paisagem.

Em síntese, os compartimentos em que o relevo mais favorece a ocupação correspondem aos CMP I e III, sendo que o primeiro, mesmo com deficiência de estradas, apresentou maior área convertida para usos antrópicos e induz a acreditar que será uma área onde a agricultura se fortalecerá. Fato curioso, pois os municípios que englobam tal região não foram contemplados com incentivos dos Planos Nacionais de Desenvolvimento (POLOCENTRO e PRODECER). E, embora o CMP III apresente limitações pedológicas, a manutenção e ampliação das pastagens aventa-se como uma 
tendência sobre as áreas de Plintossolos, assim com o aumento das áreas agrícolas sobre as manchas de Latossolos Vermelho Amarelo.

Os compartimentos que são de difícil ocupação por questões físico-estruturais, estão sob Zona de Erosão Recuante (CMP II, IV, V e VI) e são indicados para manutenção da conservação ambiental. Áreas que se ocupadas de forma indiscriminadas podem gerar inúmeros danos ao meio ambiente, sendo a fragmentação, a perda de solos e consequentemente a perda de biodiversidade as mais alarmantes.

As características evidenciadas em cada compartimento produto da delimitação pela convergência dos elementos morfopedológicos da MVP possibilitou entendimento da paisagem, que corroborou com a análise do uso ocupação evidenciando ambientes que necessitam de maior atenção na ocupação por seus aspectos físicos, e ambientes que estão preservados por serem de solos e relevo não propício à agricultura ou pastagem.

É possível destacar que o estudo a partir da compartimentação morfopedológica requer o tratamento de dados para a abordagem integrada, tornando-se assim subsídio para instrumentalizar políticas públicas de ocupação adequada a cada paisagem.

\section{Referencias Bibliográficas}

ALVES, T. S; CAMPOS, L.L.; NETO, N. E.; LOUREIRO, M. F. Biomassa e atividade microbiana de solo sob vegetação nativa e diferentes sistemas de manejos. Acta Scientiarum. Agronomy. Maringá, v. 33, n. 2, p. 341-347.2011.

ASSAD, E.D.; SANO, E, E. Sistema de informação Geográfica: aplicações na agricultura. 2 ed. ver e ampl. Brasília: EMBRAPA, 1998.

BARBALHO, M. G. S. Morfopedologia Aplicada ao Diagnóstico e Diretrizes para o Controle dos Processos Erosivos Lineares na Alta Bacia do Rio Araguaia (GO/MT). Dissertação (Mestrado em Geografia) - Instituto de Estudos Sócio-Ambientais, Universidade Federal de Goiás. Goiânia, 2002.

BARREIRA, C.C.M.A. Vão do Paranã: a estruturação de uma região. Brasília: Ministério da Integração Nacional, Universidade Federal de Goiás, 2002.

BORGES, J.C. P; SILVA, M.P.da; SILVA, W.K.L. O Estado e Regionalização em Goiás. Revista Territorial - Goiás, v.1, n.1, p.112-134, jul./dez. 2012

BRASIL. Ministério do Meio Ambiente. Mapeamento do Uso e Cobertura do Cerrado: Projeto TerraClass Cerrado 2013. Brasília: MMA,2015.

CARVALHO, F. M. V.; DE MARCO, P.; FERREIRA JUNIOR, L. G. The Cerrado into-pieces: Habitat fragmentation as a function of landscape use in the savanas of Central Brazil. Biological Conservation, 142:1392-1403, 2009.

CASTRO, S. S.; SALOMÃO, F. X. de T. Compartimentação Morfopedológica e sua aplicação: Considerações metodológicas. São Paulo: Geousp, 2000. 
CASTRO, S. S.; ABDALA, K.; SILVA, A. S.; BORGES, V. A Expansão da Cana-De-Açúcar no Cerrado e no Estado de Goiás: Elementos para uma análise espacial do Processo. Boletim Goiano de Geografia (Online), v. 30, p. 171-191, 2010.

EMBRAPA. Disponível em:

<http://www.agencia.cnptia.embrapa.br/Agencia16/AG01/arvore/AG01_43_911200585233.ht ml>. Acesso em: 08/01/2017

FARIA, K. M. S. de; NASCIMENTO, M. S.; CARNEIRO, G. T.; CASTRO, S. S. de. Análise Geoecológica da Conservação Ambiental das sub-bacias do rio Claro (GO) e do Rio Garças (MT). Revista Nordestina de Ecoturismo, v. 5, p. 111-118, 2012.

FARIA, T. O.; VECCHIATO, A. B.; SALOMÃO, F. X. T.; SANTOS Jr, W. A. Abordagem morfopedológica para diagnóstico e controle de processos erosivos. Ambi-Agua, Taubaté, v. 8, n. 2, p. 215-232, 2013.

FARIA, K. M. S. de; CASTRO, S. S. Mudanças de uso do solo na Alta Bacia do Rio Araguaia e as relações com as políticas públicas de 1975 a 2010. In: Sandro Dutra e Silva; Jose Paulo Pietrafesa; José Luiz Andrade Franco; José Augusto Drummond; Giovana Galvão Tavares.. (Org.). Fronteira Cerrado: sociedade e natureza no oeste do Brasil. 1ed.Goiânia: Editora da PUC Goiás, 2013, v. 1, p. 315-330.

FELFILI, J.M.; SOUZA-SILVA, J.C.; SCARIOT, A. Biodiversidade, ecologia e conservação do cerrado: avanços e conhecimento. IN: SCARIOT, A.; SOUZA-SILVA, J.C.; FELFILI, J.M. (org). Cerrado: ecologia, biodiversidade e conservação. Brasília: Ministério do Meio Ambiente, 2005 .

FERREIRA, L. G.; FERREIRA, M. E.;ROCHA, G.F.;NEMAYER,M.;FERREIRA,N. C. Dinâmica agrícola e desmatamentos em áreas de cerrado: uma análise a partir de dados censitários e imagens de resolução moderada. Revista Brasileira de Cartografia n. 61/02, 2009.

FERREIRA, M. E.; ANJOS, A. F.; FERREIRA, L. G.; BUSTAMANTE, M. M. C.; FERNANDES, G. W.; MACHADO, R. B. Cerrado: fim da história ou uma nova história?. Ciência Hoje, v. 56, p. 24-29, 2016.

GANEM, R. S.; DRUMMOND,J.A; FRANCO, J.L. DE A. Conservation Polices And Control Of Habitat Fragmentation In The Brazilian Cerrado Biome. Ambiente \& Sociedade. São Paulo v. XVI, n. 3 n p. 99-118 n jul.-set. 2013

GARCIA, J. R.; BUAINAIN, A. M. Dinâmica de Ocupação do Cerrado Nordestino pela Agricultura: 1990 e 20121. RESR, Piracicaba-SP, Vol. 54, No 02, p. 319-338, Abr/Jun 2016.

HERMUCHE, P. M.; SANO, E. E. Identificação Da Floresta Estacional Decidual No Vão Do Paranã, Estado De Goiás, a Partir Da Análise Da Reflectância Acumulada De Imagens Do Sensor ETM+/LANDSAT-7. RBC. Revista Brasileira de Cartografia (Online), v. 63, p. 415425, 2011.

KLINK, H. J. Geoecologia e regionalização natural: bases para a pesquisa ambiental. São Paulo: IGEO - USP, 1981.

LANG, S.; BLASCHKE, T. Análise da paisagem com SIG. Tradução Hermann Kux. São Paulo: Oficina de Textos, 2009. 
LATRUBESSE, E. M.; CARVALHO, T. M. de. Geomorfologia do Estado de Goiás e Distrito Federal. Goiânia, 2006.

MACHADO, R. B.; RAMOS NETO, M. B.; PEREIRA, P. G. P.; CALDAS, E. F., GONÇALVES, D. A.; SANTOS, N. S.; TABOR, K.; STEININGER, M. Estimativas de perda da área do Cerrado brasileiro. Relatório técnico não publicado. Conservação Internacional, Brasília, DF. 2004.

MCGARIGAL, K.; MARKS, B. J. FRASTATS: spatial pattern analysis program for quantifying landscape structure. USDA For. Serv. Gen. Tech. Rep, 1995.

MITTERMEIER R.A., TURNER W.R., LARSEN F.W., BROOKS T.M., GASCON C. Global Biodiversity Conservation: The Critical Role of Hotspots. In: ZACHOS F., HABEL J. (eds) Biodiversity Hotspots. Springer, Berlin, Heidelberg. 2011.

NUNES, E. D. Modelagem de processos erosivos em sistemas pedológicos no município de Mineiros - GO. Tese (Doutorado em geografia) - Universidade Federal de Goiás. Goiânia, 2015.

PONCIANO, T. A. Dinâmica da Estrutura da Paisagem na Microrregião do Vão Do Paranã $(G o)$. Goiânia, GO. Originalmente apresentada como dissertação de mestrado, Universidade Federal de Goiás, 2017.

REZENDE, G. C. de. Ocupação agrícola e estrutura agrária no cerrado: o papel do preço da terra, dos recursos naturais e da tecnologia. Textos para Discussão. IPEA 2002. Disponível em: http://repositorio.ipea.gov.br/handle/11058/2803. Acesso em maio de 2017.

RIBEIRO, J.F.; WALTER, B.M.T. As principais fitofisionomias do Bioma Cerrado. In: SANO, S.M.; ALMEIDA, S.P.; RIBEIRO, J.F. (eds.) Cerrado: ecologia e flora. Embrapa Cerrados, Planaltina. 2008. p.151 -212.

ROCHA, G.F.; FERREIRA JÚNIOR, L. G.; FERREIRA, N. C.; FERREIRA, M. E. Detecção de desmatamentos no bioma Cerrado entre 2002 e 2009: padrões, tendências e impactos. RBC. Revista Brasileira de Cartografia (Online), v. 63, p. 341-349, 2011

SANO, E. E.; DAMBROS, L. A; OLIVEIRA, G. C.; BRITES, R. S. Padrões de cobertura de solos do Estado de Goiás. In: Ferreira, L.G. (Org.). A Encruzilhada Socioambiental.

Biodiversidade, Economia e Sustentabilidade no Cerrado. Goiânia: Ed. da UFG, 2008, v., p. 91-106.

SANO, E.E.; ROSA, R.; BRITO, J.L.S.; FERREIRA JR., L.G. Land cover mapping of the tropical savanna region in Brazil. Environmental Monitoring and Assessment, v. 166, p. 113124,2010 .

SANTOS J. G. R. dos; CASTRO S. S. de. Influência Do Meio Físico Na Produção Dos Assentamentos Rurais Das Regiões Do Sul E Do Nordeste Goiano. Soc. \& Nat., Uberlândia, 28 (1): 95-116, jan/abr/2016.

SANTOS, M. B.; FARIA, K.M.S. Uso de modelagens espaciais para análise de risco a incêndio: análise preliminar para a região norte de Goiás In: PEREZ FILHO, A; AMORIN, R.R. Os Desafios da Geografia Física na Fronteira do Conhecimento.1, 2017, v.1, p. 58115815 
SILVA, M. A. et al. Flora vascular do Vão do Paranã, Estado de Goiás, Brasil. Boletim do Herbário Ezechias Paulo Heringer. Brasília, DF, v. 14, n. 1, p. 49-127, 2004.

TORBICK, N., LUSCH, D., QI, J., MOORE, N., OLSON, J. and GE, J., Developing land use/ land cover parameterization for climate-land modelling in East Africa. International Journal of Remote Sensing, 27, pp. 4227-4244. 2006.

TRICART, J. Ecodinâmica. Rio de Janeiro: SUPREN, 1977

TRICART, J.; KILIAN, J. L'éco-Geografie et l'amenagement du Milieu Naturel. Paris: Maspero, p. 325. 1979.

TRINDADE, P. S. Aptidão Agrícola, Mudanças de Usos Dos Solos, Conflitos e Impactos Diretos e Indiretos da Expansão da Cana-De-Açúcar na Região Sudoeste Goiano. Doutorado em Ciências Ambientais. Universidade Federal de Goiás, UFG, Brasil. 2015.

YAZIGI, R. B. S. A nova realidade do Nordeste Goiano. 2000. Disponível em:.<http://www.imb.go.gov.br/pub/conj/conj3/06.htm>. Acesso em: 13/01/2016.

Agradecimentos: Ao Conselho Nacional de Desenvolvimento Científico e Tecnológico (CNPq) que subsidia o projeto "Geoecologia da paisagem: Dinâmicas e integridades socioambientais da Microrregião do Vão do Paranã - Goiás", aprovado pela chamada MCTI/CNPq No 01/2016, ao qual se vincula esse artigo.

Tássia Andrielle Ponciano

Mestre em Ciências Ambientais pela Universidade Federal de Goiás. Campus Samambaia. Cep: 74690-900 - Goiânia, GO - Brasil.

E-mail: tassiaponciano@gmail.com

Hellbia Samara Moreira de Carvalho Rodrigues

Em doutoramento e Mestre em Geografia pela Universidade Federal de Goiás. Campus Samambaia. Cep:74690-900 - Goiânia, GO - Brasil.

E-mail: hellbiageografia1@gmail.com

Karla Maria Silva de Faria

Doutora e Mestre em Geografia pela Universidade Federal de Goiás. Atualmente é professora dos Programas de Pós-Graduação em Ciências Ambientais (CIAMB) e em Geografia (PPGEO), ambos da Universidade Federal de Goiás (UFG). Campus Samambaia. Cep: 74690-900 - Goiânia, GO - Brasil.

E-mail: karla_faria@ufg.br 